\title{
COMUNICAR E INFORMAR AL ESTUDIANTADO: RETOS DE LOS COMPROMISOS DE MEJORAMIENTO DE LAS CARRERAS UNIVERSITARIAS
}

\author{
COMMUNICATE AND INFORM STUDENTS: CHALLENGES FOR THE \\ UNIVERSITIES' COMMITMENT WITH IMPROVEMENT
}
COMMUNIQUER ET INFORMER LES ETUDIANTS: LES DEFIS DES ENGAGEMENTS D'AMELIORATION DES FILIERES UNIVERSITAIRES

\author{
Alexandra Arrieta Espinoza1 \\ alexandra.arrieta@ucr.ac.cr \\ Elsiana Guido Guido ${ }^{2}$ \\ elsiana.guido@ucr.ac.cr \\ Universidad de Costa Rica, Costa Rica
}

\author{
Volumen 8, Número 1 \\ 30 de mayo de 2017
}

pp. 54 - 93

Recibido: 12 diciembre de 2016

Aprobado: 29 de abril de 2017

1 Mag. en Diplomacia. Licenciatura en Literatura Francesa. Bachiller en la Enseñanza del Francés. Universidad de Costa Rica. Docente e investigadora Escuela de Lenguas Modernas. Universidad de Costa Rica. alexandra.arrieta@ucr.ac.cr

2 Mag. en Psicopedagogía. Licenciatura en Administración de Programas educativos no Formales y Bachiller en Ciencias Políticas. Universidad de Costa Rica. Asesora del Centro de Evaluación Académica y de la Vicerrectoría de Docencia. Universidad de Costa Rica. elsiana.guido@ucr.ac.cr

Comunicar e informar al estudiantado: retos de los compromisos de mejoramiento de las carreras universitarias

Alexandra Arrieta Espinoza y Elsiana Guido Guido

DOI: http://dx.doi.org/10.22458/caes.v8i1.1773

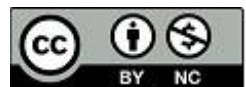

Artículo protegido por licencia Creative Commons 


\section{Resumen}

Este artículo presenta un estudio realizado en el marco del compromiso de mejoramiento resultante de un proceso de autoevaluación de la carrera de Bachillerato en Francés. El estudio, realizado por docentes de la comisión de autoevaluación de la carrera, contó con la asesoría del Centro de Evaluación Académica e indagó sobre los medios de información y comunicación más utilizados por su estudiantado, con el fin de optimizar la divulgación y la comunicación de temas relativos a la carrera. Los resultados obtenidos reflejan que, posiblemente como resultado del desarrollo tecnológico, las personas universitarias jóvenes privilegian la comunicación de aspectos académicos por medios más dinámicos y que las unidades académicas no utilizan el mismo canal de comunicación que usan y prefieren estos; esta situación supone retos para el diseño de estrategias de divulgación de diversos aspectos académicos derivados de los procesos de calidad y mejora continua de las carreras universitarias, en donde se transita de un modelo de comunicación de masas - unidireccional- a un modelo de comunicación en red - más horizontal.

Palabras clave: Autoevaluación; certificación; compromiso de mejoramiento; francés; divulgación; medios; información; comunicación.

\section{Abstract}

This article presents a study made conducted in the framework of a self-evaluation process of the French Language Baccalaureate program at the Universidad de Costa Rica (UCR) in 2015. The study was carried out by THE staff in charge of the self-evaluation process, and relied on the advice of the Center for Academic Evaluation. It examines the communication and information media or mechanisms that were most used by the students, in order to improve the communication of information related to the program. The results of the study suggest that young university students prefer more dynamic media, while the academic units tend to privilege other communication channels. This situation poses a challenge regarding the design of the communication strategies to be used to convey aspects of the quality assurance and continuous improvement plans of the university majors. A transition from unidirectional mass-communication schemes to more horizontal networking schemes is to be expected.

Keywords: self-evaluation process; commitment to improvement; quality certification; media; information; communication

Comunicar e informar al estudiantado: retos de los compromisos de mejoramiento de las carreras universitarias

Alexandra Arrieta Espinoza y Elsiana Guido Guido

DOI: http://dx.doi.org/10.22458/caes.v8i1.1773

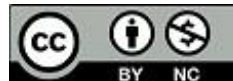

Artículo protegido por licencia Creative Commons 


\section{Résumé}

Cet article porte sur une étude réalisée dans le cadre de l'engagement d'amélioration continue, résultant du processus d'autoévaluation de la filière de français. L'étude, réalisée par des enseignants du Comité d'autoévaluation de la filière, a été assistée par le Centre d'Évaluation académique et s'est renseignée sur les moyens de communication les plus utilisés par les étudiants; afin d'optimiser la divulgation et la communication de thèmes en rapport avec la filière. Les données obtenues reflètent que probablement comme résultat du développement technologique, les jeunes universitaires privilégient la communication des aspects académiques par des moyens plus dynamiques et que les unités académiques n'utilisent pas le même canal de communication que cette population; cette situation suppose des défis dans l'élaboration des stratégies de divulgation de divers aspects académiques dérivés des processus de qualité et d'amélioration continue des filières universitaires, où I'on transite d'un modèle de communication des masses -unidirectionnel- à un modèle de communication en réseau- plus horizontal-.

Mots clés: Autoévaluation, certification, engagement d'amélioration, français, divulgation, médias, information, communication.

\section{Introducción}

\section{Desarrollo histórico de la carrera}

La carrera de Bachillerato en Francés de la Universidad de Costa Rica (UCR) tiene sus orígenes en la década de 1950, según consta en el informe final de autoevaluación de la carrera (Universidad de Costa Rica, 2012). El 26 de mayo de 1956 se crea la Sección de Idiomas en el Departamento de Filología, Lingüística y Literatura, y a partir de entonces se estructura un plan de estudios para un Profesorado de Segunda Enseñanza compartido con la Facultad de Educación. En 1961 se graduó la primera generación de esta carrera. En ese año se estableció, además, el programa de Licenciatura en Ciencias y Letras. El 19 de septiembre de 1963 se creó el Departamento de Lenguas Extranjeras y un año después, se

Comunicar e informar al estudiantado: retos de los compromisos de mejoramiento de las carreras universitarias

Alexandra Arrieta Espinoza y Elsiana Guido Guido

DOI: http://dx.doi.org/10.22458/caes.v8i1.1773

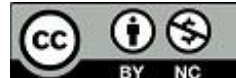

Artículo protegido por licencia Creative Commons 
establecen planes de estudios que incluyen programas para la formación de bachilleres en francés.

Posteriormente, se realizan modificaciones curriculares periódicas tendientes a mejorar los currículos existentes. Entre 1971 y 1972 se realizan los trámites necesarios para que el Departamento de Lenguas Extranjeras se convierta en escuela. En 1973, como resultado del III Congreso Universitario, el Departamento de Lenguas Modernas se convierte en la Escuela de Lenguas Modernas. Un año después, el Estatuto Orgánico de la Universidad de Costa Rica en el Capítulo VIII, Artículo 80, estipula que la Facultad de Letras está constituida por las Escuelas de: Filología, Filosofía y Lenguas Modernas. Así se consolida la Escuela de Lenguas Modernas.

La carrera de Bachillerato en Francés tiene como propósito formar profesionales competentes en lengua, literatura y cultura francesa y francófona, desde una perspectiva humanista para desarrollar el pensamiento crítico y satisfacer las demandas de la sociedad costarricense mediante la docencia, investigación y acción social. Así mismo, aspira a fortalecer la excelencia académica para responder a los desafíos de la sociedad actual.

En el año 2008, la carrera de Bachillerato en Francés inició el proceso de autoevaluación que culminó con la certificación de calidad otorgada por la Universidad de Costa Rica en el año 2014. Para la realización del proceso de autoevaluación se utilizó el Manual de Autoevaluación de la agencia Sistema Nacional de Acreditación de la Educación Superior (SINAES) del año 2000.

Comunicar e informar al estudiantado: retos de los compromisos de mejoramiento de las carreras universitarias

Alexandra Arrieta Espinoza y Elsiana Guido Guido

DOI: http://dx.doi.org/10.22458/caes.v8i1.1773

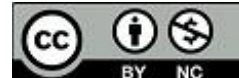


Actualmente, se encuentra cumpliendo los objetivos de su Compromiso de Mejoramiento (CM) adquirido al certificarse. Como parte de los objetivos de ese compromiso de mejoramiento, la carrera debe desarrollar una estrategia que le permita una mayor y mejor difusión de la información a sus estudiantes y poblaciones vinculadas con la carrera.

De esta manera, se plantea la realización de un estudio para indagar sobre los medios de comunicación más utilizados por la población estudiantil de la carrera de Bachillerato en francés, el cual se llevó a cabo a finales del año 2015.

\section{Referentes teóricos}

\subsection{Procesos de certificación en la Universidad de Costa Rica: reseña histórica}

La carrera de Bachillerato en Francés, impartida por la Facultad de Letras, obtuvo la certificación de calidad otorgada por la UCR en el año 2014. De acuerdo con el Diccionario en línea de la Real Academia Española, certificar se refiere a "asegurar, afirmar, dar por cierto algo". El concepto también hace referencia a "hacer constar por escrito una realidad de hecho por quien tenga fe pública o atribución para ello" (RAE).

La primera vez que el concepto de certificación fue utilizado en la UCR fue en el año 2008 cuando la Vicerrectoría de Docencia (VD) emitió, en febrero de ese año, la Corrección a la Resolución VD-R-7042-2001, en la que acuerda brindar la opción de la certificación de calidad a las unidades académicas que opten por un proceso de autoevaluación para el mejoramiento y no deseen ser acreditadas por una agencia externa (p. 9). Así mismo, en la resolución se establece que, para la obtención del certificado de calidad, el Centro de

Comunicar e informar al estudiantado: retos de los compromisos de mejoramiento de las carreras universitarias

Alexandra Arrieta Espinoza y Elsiana Guido Guido

DOI: http://dx.doi.org/10.22458/caes.v8i1.1773

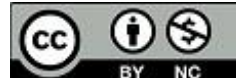

Artículo protegido por licencia Creative Commons 
Evaluación Académica (CEA) y la VD dictaminarán de acuerdo con los criterios y procedimientos que se establezcan.

En la adición a la Resolución del año 2008, también se señalan los procedimientos que deben cumplir las carreras que deseen optar por el proceso de autoevaluación para el mejoramiento y quieran obtener la certificación de calidad de la UCR, dentro de los que se incluyen la realización de un proceso de autoevaluación y la elaboración de un plan preliminar de mejoramiento (p.5). El proceso incluye, además, la valoración externa por parte de un equipo de pares externos a la unidad académica y la elaboración del plan final de mejoramiento, tomando en consideración las observaciones emitidas por el equipo de pares externos (pp. 5-6).

Finalmente, en ese documento citado se establece que será el CEA y la Vicerrectoría de Docencia, quienes dictaminarán, de acuerdo con los criterios y procedimientos que se establezcan, la obtención de la certificación de calidad de una carrera (p. 6).

Siete años después, en la Resolución VD-R-9227-2015 publicada por la VD en el mes de junio de 2015, se establecen las nuevas disposiciones para los procesos de autoevaluaciónautorregulación, orientados al mejoramiento, certificación, acreditación y reacreditación de carreras de grado de la institución (p.3). En esta Resolución se acuerda una definición del término certificación en el sentido de un "[...] reconocimiento interno de la calidad y la excelencia que otorga la Universidad de Costa Rica [...]" a las carreras.

Comunicar e informar al estudiantado: retos de los compromisos de mejoramiento de las carreras universitarias

Alexandra Arrieta Espinoza y Elsiana Guido Guido

DOI: http://dx.doi.org/10.22458/caes.v8i1.1773 
En la Resolución VD-R-9227-2015 se ratifica que es competencia de la VD la decisión de otorgar la certificación a una carrera, cuando se estipula que dentro de sus funciones tiene lo siguiente: "Dictaminar, en coordinación con el CEA, la certificación que otorga la Universidad de Costa Rica a las carreras que han solicitado esta opción, de acuerdo con el cumplimiento de los criterios, estándares y procedimientos establecidos para tal efecto" (p. 10).

Por otro lado, se indica en el documento del año 2015, que le corresponde al CEA lo siguiente:

Validar los procesos y resultados de la autoevaluación con miras a la certificación por parte de la institución. Para ello, el CEA hará uso de procedimientos específicos, con el fin de recomendar a la Vicerrectoría de Docencia otorgar o no este reconocimiento (p.11).

En cuanto a la metodología que se utiliza para el proceso de autoevaluación que les permite a las carreras optar por certificación de la calidad, se indica que, a diferencia de cuando se opta por la acreditación con una agencia acreditadora, se debe "[...] ejecutar el proceso de autoevaluación, en el marco de los lineamientos establecidos por el CEA [...]" (p.17).

Más recientemente, en octubre del año 2016 la VD publica un documento titulado Certificación de la calidad académica: carreras de grado, en el que se precisa el término y se detallan los lineamientos, las etapas y los procedimientos para la certificación en la UCR. En esta oportunidad se amplía la definición de certificación de la manera siguiente:

En términos generales la Certificación de la Calidad Académica que extiende la VD a las carreras que han completado este proceso, corresponde a un reconocimiento, ante la comunidad universitaria, que la carrera ha mostrado evidencia suficiente de que

Comunicar e informar al estudiantado: retos de los compromisos de mejoramiento de las carreras universitarias

Alexandra Arrieta Espinoza y Elsiana Guido Guido

DOI: http://dx.doi.org/10.22458/caes.v8i1.1773

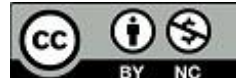

Artículo protegido por licencia Creative Commons 
cumple con un conjunto de condiciones de calidad académica deseadas, reconocimiento que se extiende por un periodo de cinco años, durante los cuales, a la luz de los compromisos de mejora, la carrera y la institución articulan esfuerzos y recursos para superar las debilidades identificadas, dando especial atención al desarrollo de condiciones de sostenibilidad que potencien dicha superación (Vicerrectoría de Docencia, 2016, p 10).

A pesar de toda la normativa generada por la UCR, a la fecha solo han obtenido la certificación de la calidad tres carreras: una de la Facultad de Educación, otra de la Facultad de Bellas Artes y la tercera de la Facultad de Letras.

Tanto las carreras que opten por los procesos de autoevaluación con fines de acreditación como las que optan por la certificación otorgada por la UCR deben elaborar un compromiso de mejoramiento, y darle seguimiento a los objetivos consignados en ese documento que es avalado por la Rectoría de la Universidad.

\subsection{Compromisos de mejoramiento y aseguramiento de la calidad}

Como bien lo apuntan Alberto Jaramillo y Ángela M. Montoya (2007), el objetivo final de la autoevaluación es mejorar la calidad de la carrera y esto, según los autores, se posibilita

[...] en la medida en que se identifiquen las oportunidades de mejoramiento, se tracen objetivos para ellas y se emprendan las acciones correspondientes; es decir, incrementar la calidad de un programa o institución exige la formulación, ejecución y seguimiento de un plan de mejoramiento (p.23).

Una vez que una carrera finaliza el proceso de autoevaluación y ha elaborado un informe en donde evalúa el estado actual de la misma, según los criterios establecidos durante el proceso, se elabora un Compromiso de Mejoramiento (CM). Tal y como lo plantean Guido,

Comunicar e informar al estudiantado: retos de los compromisos de mejoramiento de las carreras universitarias

Alexandra Arrieta Espinoza y Elsiana Guido Guido

DOI: http://dx.doi.org/10.22458/caes.v8i1.1773

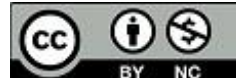

Artículo protegido por licencia Creative Commons 
Calderón y Gallardo (2011), al citar el Manual de Acreditación. Convocatoria año 2000 del Sistema Nacional de Acreditación de Educación Superior, para esa agencia acreditadora el compromiso de mejoramiento plantea el desarrollo de las acciones que, a criterio de las poblaciones consultadas en el proceso de autoevaluación, influyen, o pueden influir, de manera directa en el mantenimiento o en la mejora de los niveles de calidad. (Guido, Calderón y Gallardo, 2011, p.3). De esta forma, proponen las autoras "[...] se concibe al plan de mejora como el resultado de la interacción de fuerzas, de actores y de autoridades universitarias, que reflejan el acuerdo o negociación de todas las partes implicadas en el proceso de autoevaluación" (p. 4).

Posteriormente, el proceso de ejecución de los objetivos planteados en el compromiso de mejoramiento se enmarca dentro de las acciones realizadas por las carreras para asegurar la calidad de sus procesos. Para Gonzalo Zapata e Ivo Tejeda (2009), el aseguramiento de la calidad hace referencia a las "[...] políticas, procedimientos, normas y prácticas (internas y externas a las instituciones y sus programas) destinadas a la mantención y promoción de estándares de calidad, así como a su divulgación y transparencia en el sistema" (p.193).

\subsection{Toma de decisiones y gestión interna de la calidad.}

Según lo plantea Toro (2012), las instituciones de educación superior (IES) por un lado deben cumplir lo que él denomina sus propósitos institucionales y por otro satisfacer las demandas de la sociedad, entendiendo por esto último no únicamente las exigencias del mercado laboral, sino también de la comunidad académica y de la sociedad en general (p.191). A la primera de estas exigencias le denomina el autor consistencia interna y a la

Comunicar e informar al estudiantado: retos de los compromisos de mejoramiento de las carreras universitarias

Alexandra Arrieta Espinoza y Elsiana Guido Guido

DOI: http://dx.doi.org/10.22458/caes.v8i1.1773

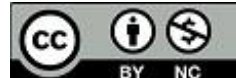

Artículo protegido por licencia Creative Commons 
segunda consistencia externa, y de ahí deriva que la calidad de una institución es "[...] una medida del logro de la consistencia interna y externa" (Toro, 2012, p.191).

Dentro de esta concepción de calidad, la evaluación le permite conocer a la institución o a las carreras, lo que se logra según lo planeado, para lo que la evaluación debe no solo ser "de estado" como Toro lo plantea, es decir, que presenta la situación actual de la carrera según sus principales indicadores; sino que también debe ser "explicativa", en el sentido de que "[...] intenta dar razón del desempeño de los diversos procesos que componen la operación de las IES" (Toro, 2012, p.192). Lo importante de este último tipo de evaluación es que permite elaborar los compromisos o planes de mejora ya que, según el autor, "este documento concentra su interés en las evaluaciones explicativas por considerarlas piezas indispensables dentro de una gestión de calidad efectiva" (Toro, 2012, p. 192).

Los compromisos o planes de mejoramiento presentan entonces, según Toro, la relación e interacción de los recursos (físicos, humanos, computacionales, financieros, entre otros) y los factores que tienen influencia directa con la calidad de la carrera (Toro, 2012, p. 194). Dentro de esto, para el autor, los compromisos o planes de mejoramiento presentan las interacciones entre los recursos y entre los factores que pueden afectar la calidad de manera decidida, tales como procesos de selección de estudiantes o de docentes, procesos de formación y de evaluación de docentes, procesos de comunicación y divulgación.

Los procesos de comunicación y divulgación constituyen una interacción relevante para la calidad de la carrera en la medida en que, siguiendo el planteamiento de Toro, permite

Comunicar e informar al estudiantado: retos de los compromisos de mejoramiento de las carreras universitarias

Alexandra Arrieta Espinoza y Elsiana Guido Guido

DOI: http://dx.doi.org/10.22458/caes.v8i1.1773

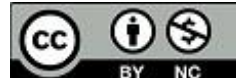

Artículo protegido por licencia Creative Commons 
gestionar el material informativo, entre las poblaciones relevantes para la carrera en términos de estrategias de comunicación que mejoren el proceso educativo.

Tal y como lo expone Alarcón (2016), la gestión interna de calidad de una carrera debe de estar basada en sistemas de información, así como en estudios que respalden las decisiones que se tomen. De acuerdo con el autor, la gestión de la calidad implica, entonces, que las decisiones tengan como referente los resultados obtenidos en indagaciones o estudios y que, las bases de datos sean la fuente que permita sustentar las decisiones, de manera tal que la carrera, y sobre todo, sus órganos de dirección puedan tomar decisiones estratégicas (diapositiva 47).

Es en el sentido anterior, que se vuelven imprescindibles dentro de un contexto de gestión de la calidad, la elaboración de sistemas integrados de información y la disponibilidad de indicadores diversos que faciliten la toma de decisiones.

De manera similar, Toro (2012) señala que la gestión de la calidad conlleva, por un lado, la recopilación de información referente al funcionamiento de la carrera o de la universidad (indicadores), pero por otro lado, y esa es la connotación que interesa en este artículo, implica un proceso de investigación y desarrollo, ya que, según el autor, la gestión de la calidad se convierte en "[...] una actividad de investigación de procesos docentes (o de investigación) que involucra profesores como actores centrales y diversas unidades que apoyen dicha investigación" (p. 198). Los procesos de gestión de calidad nutren la formulación de compromisos o planes de mejoramiento, y también su ejecución y seguimiento.

Comunicar e informar al estudiantado: retos de los compromisos de mejoramiento de las carreras universitarias

Alexandra Arrieta Espinoza y Elsiana Guido Guido DOI: http://dx.doi.org/10.22458/caes.v8i1.1773

\section{(c) (1) (3)}


De este modo, para la elaboración de estrategias de comunicación y de divulgación dirigidas al estudiantado de una carrera, es importante que se realicen los estudios pertinentes que le permitan a las carreras obtener información acerca de por lo menos los aspectos siguientes:

a) Las características básicas del estudiantado: que permita elaborar una base de datos con información actualizada con el nombre de estudiante, correo electrónico que utiliza, número de teléfono, año que cursa en la carrera.

b) Los medios que utiliza el estudiantado para informarse: lo que posibilita realizar un inventario de dos aspectos, por un lado del nivel de información que el estudiantado considera tener acerca de lo que acontece en la carrera y, por otro lado, acerca de los principales medios de comunicación que utiliza frecuentemente.

c) Los contenidos acerca de los cuales le gustaría recibir información: para poder seleccionar la información más pertinente y apropiada, según las necesidades e intereses de este grupo.

d) Medios más utilizados para la comunicación entre pares: para conocer acerca de los hábitos de comunicación entre los jóvenes estudiantes.

\section{La comunicación y divulgación como aspecto medular del compromiso de mejoramiento en la carrera de Bachillerato en Francés}

El proceso de autoevaluación de la carrera de Bachillerato en Francés se llevó a cabo tomando como referencia los lineamientos establecidos por la Agencia SINAES, en el Manual de Acreditación del año 2000. Este manual contenía seis dimensiones, a saber: personal

Comunicar e informar al estudiantado: retos de los compromisos de mejoramiento de las carreras universitarias

Alexandra Arrieta Espinoza y Elsiana Guido Guido

DOI: http://dx.doi.org/10.22458/caes.v8i1.1773

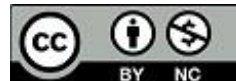

Artículo protegido por licencia Creative Commons 
académico, currículum, estudiantes, administración de la carrera, infraestructura y equipamiento e impacto y pertinencia.

En la Tabla No. 01 se resume, de manera cuantitativa, el CM de la carrera, cuya vigencia comprende desde el año 2014 hasta el año 2017. De los datos, se resalta que la carrera presenta 24 aspectos por mejorar, distribuidos en todos los componentes que conforman el modelo que se siguió durante el proceso de autoevaluación; estas debilidades generaron, a su vez, un total de 37 objetivos, a los que tiene que darle seguimiento la carrera durante su período de certificación. Sin embargo, los dos componentes con mayor número de debilidades consignadas en ese documento, corresponden a currículum y personal académico, con 7 y 5 debilidades, respectivamente.

Tabla No. 01

\section{Bachillerato en Francés}

Resumen cuantitativo del Compromiso de Mejoramiento 2014-2017

\begin{tabular}{|l|c|c|}
\hline $\begin{array}{l}\text { Dimensión del modelo de } \\
\text { acreditación agencia SINAES }\end{array}$ & $\begin{array}{l}\text { Número de debilidades } \\
\text { por dimensión } \\
\text { relacionados } \\
\text { debilidad }\end{array}$ \\
\hline Personal académico & 5 & 9 \\
\hline Currículum & 7 & 10 \\
\hline Estudiantes & 2 & 4 \\
\hline Administración de la carrera & 3 & 4 \\
\hline Infraestructura y equipamiento & 4 & 5 \\
\hline Impacto y pertinencia & 3 & 5 \\
\hline \multicolumn{1}{|c|}{ Total: } & $\mathbf{2 4}$ & $\mathbf{3 7}$ \\
\hline
\end{tabular}

Fuente: Compromiso de mejoramiento Bachillerato en Francés 2014-2017

Comunicar e informar al estudiantado: retos de los compromisos de mejoramiento de las carreras universitarias

Alexandra Arrieta Espinoza y Elsiana Guido Guido

DOI: http://dx.doi.org/10.22458/caes.v8i1.1773

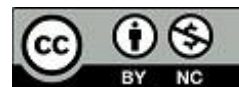


El CM de la carrera de Bachillerato en Francés contiene varios aspectos relacionados con la necesidad de mejorar la divulgación y la comunicación, dirigida a diversas poblaciones internas y externas a la Unidad Académica. Las principales poblaciones identificadas, a las cuales se deben direccionar esfuerzos en ese sentido son el estudiantado, docentes, empleadores, personas graduadas y a los diversos sectores francófonos de la sociedad, que se consideran sus interlocutores.

En la tabla No. 02 se sintetizan las debilidades contenidas en el CM de la carrera, que contemplan objetivos relacionados con los temas de la comunicación y divulgación. Como se puede observar, este aspecto se encuentra en tres dimensiones diferentes y comprende acciones dirigidas al estudiantado y cuerpo docente.

Los objetivos del CM fueron redactados de manera tal que, por medio del desarrollo de estrategias de comunicación y divulgación se posibilitaran varias acciones, a saber: mejorar el conocimiento que tiene el estudiantado sobre diversos reglamentos académicos y normas universitarias, así como, mejorar los conocimientos que tiene esta población sobre el plan de estudios y sobre su condición de estudiantes durante el desarrollo del programa de la carrera del Bachillerato en Francés. Además, durante el proceso de autoevaluación se evidenció la necesidad de realizar acciones tendientes a mejorar la difusión de información relativa a las funciones que tiene el personal administrativo, tanto entre la población docente como entre la estudiantil, para promover, de este modo, una mejor interacción entre las partes.

Comunicar e informar al estudiantado: retos de los compromisos de mejoramiento de las carreras universitarias

Alexandra Arrieta Espinoza y Elsiana Guido Guido

DOI: http://dx.doi.org/10.22458/caes.v8i1.1773

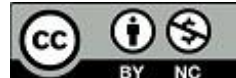


Tabla No. 02

\section{Bachillerato en Francés}

\section{Compromiso de Mejoramiento 2014-2017}

Debilidades y objetivos, por dimensión, contenidos en el $\mathrm{CM}$, relacionados con los temas de comunicación y divulgación.

\begin{tabular}{|c|c|c|}
\hline $\begin{array}{c}\text { Dimensión del modelo } \\
\text { de acreditación } \\
\text { agencia SINAES }\end{array}$ & Debilidad & Objetivo \\
\hline \multirow[t]{2}{*}{ Currículum } & $\begin{array}{l}\text { Conocimiento insuficiente por } \\
\text { parte del estudiantado sobre los } \\
\text { reglamentos establecidos por el } \\
\text { Régimen Académico Estudiantil. }\end{array}$ & $\begin{array}{l}\text { Mejorar las estrategias de } \\
\text { lomunicación y divulgación de la } \\
\text { información pertinente a la } \\
\text { población estudiantil. }\end{array}$ \\
\hline & $\begin{array}{l}\text { Desconocimiento de las normas } \\
\text { académicas universitarias, por } \\
\text { parte de los/las estudiantes y de } \\
\text { los/las docentes }\end{array}$ & $\begin{array}{l}\text { Diseñar una estrategia de } \\
\text { divulgación de la reglamentación } \\
\text { universitaria vigente, ponerla en } \\
\text { funcionamiento y evaluarla de } \\
\text { manera periódica. }\end{array}$ \\
\hline Estudiantes & $\begin{array}{l}\text { La carrera no ha logrado } \\
\text { despertar el interés en los } \\
\text { estudiantes para que conozcan } \\
\text { en detalle el Plan de estudios y } \\
\text { sus derechos y obligaciones. }\end{array}$ & $\begin{array}{|lll|}\text { Diseñar una estrategia } & \text { de } \\
\text { divulgación del "Plan } & \text { de } \\
\text { estudios" y de la "condición de } \\
\text { estudiantes" durante el desarrollo } \\
\text { del programa de la carrera del } \\
\text { Bachillerato en Francés }\end{array}$ \\
\hline Administración & \begin{tabular}{|l} 
La carrera requiere reforzar la \\
difusión de información de las \\
funciones de su personal \\
administrativo
\end{tabular} & $\begin{array}{l}\text { Difundir dicha información entre } \\
\text { docentes y estudiantes para } \\
\text { lograr una mejor interacción } \\
\text { entre las partes }\end{array}$ \\
\hline
\end{tabular}

Fuente: Compromiso de mejoramiento Bachillerato en Francés 2014-2017

Comunicar e informar al estudiantado: retos de los compromisos de mejoramiento de las carreras universitarias

Alexandra Arrieta Espinoza y Elsiana Guido Guido

DOI: http://dx.doi.org/10.22458/caes.v8i1.1773

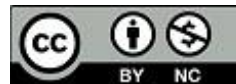


La Comisión de Autoevaluación y Certificación de la Calidad de la carrera, designada por la Dirección de la Escuela para la realización del proceso de certificación, se encargó de la ejecución del CM. Con tal propósito, dicha Comisión distribuyó la ejecución de las actividades por componentes y funciones manteniendo la divulgación como eje de todos los componentes. Tal como se muestra en el Diagrama No. 01.

\section{Diagrama No 01}

\section{Bachillerato en Francés}

Organización de la Comisión de Autoevaluación y Certificación de la Calidad para la ejecución del CM de la carrera de Bachillerato en Francés 2014-2017

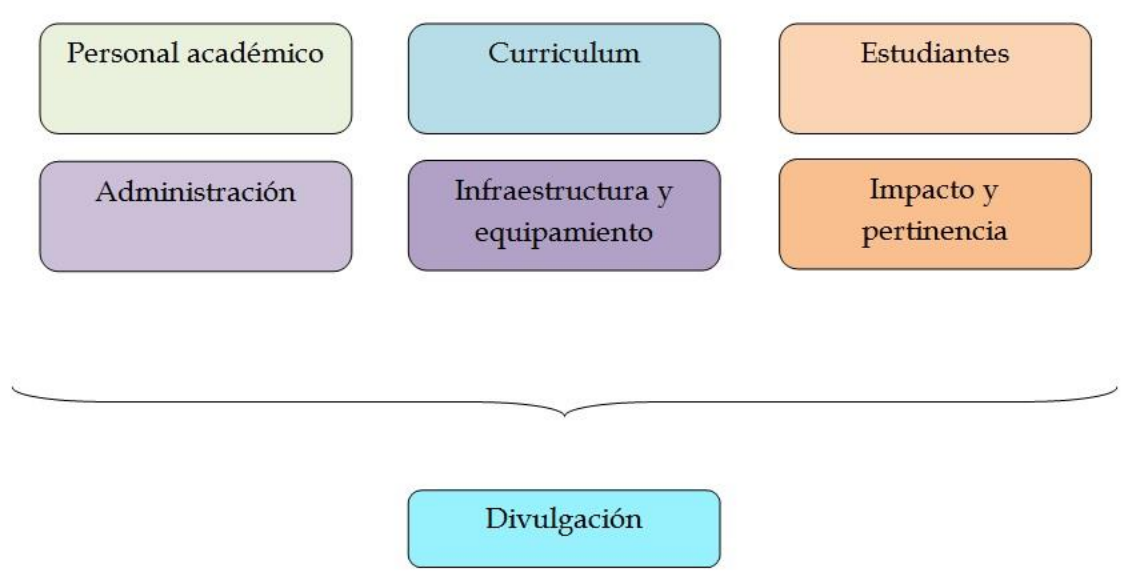

Fuente: Tomado del II Informe de Avance de Cumplimiento del Compromiso de Mejoramiento. 2015. Bachillerato en Francés. Adaptado por las autoras.

Comunicar e informar al estudiantado: retos de los compromisos de mejoramiento de las carreras universitarias

Alexandra Arrieta Espinoza y Elsiana Guido Guido

DOI: http://dx.doi.org/10.22458/caes.v8i1.1773

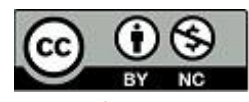




\section{1 ¿Cómo se comunican las personas jóvenes?}

Dos conceptos importantes se asumen en este artículo, a saber: persona joven y estudiante universitario. Según la definición de las Naciones Unidas (2016):

Los jóvenes son las personas con edades comprendidas entre los 15 y los 24 años de edad. La UNESCO entiende que los jóvenes constituyen un grupo heterogéneo en constante evolución y que la experiencia de "ser joven", varía mucho según las regiones del planeta e incluso dentro de un mismo país (p.1).

En lo que respecta a lo que se entiende por estudiante universitario, el Reglamento de Régimen Académico Estudiantil de la UCR (Universidad de Costa Rica, 2001) estipula que estudiantes de pregrado y de grado son "[...] aquellos que, cumpliendo todos los requisitos establecidos por la Universidad, ingresan a ella, con el propósito de obtener cualesquiera de los grados académicos que ofrece la Institución" (p.1, artículo 2).

Dado el vertiginoso desarrollo tecnológico, actualmente existe una marcada tendencia por parte de la población juvenil, en diferentes partes del mundo, a utilizar el Internet y las redes sociales como medios de información, comunicación y entretenimiento. De esta manera, Naval y Sábada (2005) en su estudio sobre juventud y medios de comunicación en el contexto de la sociedad española, afirman que

[...] música, revistas y, por supuesto, videojuegos, ordenador, Internet y teléfono móvil se han convertido en medios familiares para la juventud, donde encuentra los contenidos que le interesan, y sobre todo una herramienta que le permite satisfacer su curiosidad y su necesidad de comunicarse con sus iguales (p.12).

Asimismo, señalan que "[...] desde la perspectiva juvenil, los medios raramente son causa de sorpresa ya que siempre han estado a su alrededor, son imprescindibles para entender su cultura y un elemento clave en su proceso de socialización"(p.12).

Comunicar e informar al estudiantado: retos de los compromisos de mejoramiento de las carreras universitarias

Alexandra Arrieta Espinoza y Elsiana Guido Guido

DOI: http://dx.doi.org/10.22458/caes.v8i1.1773

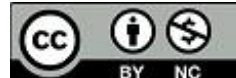

Artículo protegido por licencia Creative Commons 
Siempre en el contexto español, Urrutia (2012), en un estudio realizado en el País Vasco sobre los medios de comunicación utilizados por la población de esa región, concluye que [...] el uso de internet establece "una frontera clara" entre la generación de jóvenes y la de adultos, de manera que los jóvenes "se apoyan de manera mayoritaria" en internet para desarrollar las funciones tradicionales de los medios de comunicación, en relación a los mayores de 29 años (p.1).

Por otro lado, este mismo autor señala que

[...] el uso de las redes sociales por parte de los jóvenes es generalizada, con un 83 por ciento de usuarios, frente al 21 por ciento de usuarios adultos. Entre los primeros, el 78 por ciento usa Facebook y el 73 por ciento Tuenti, mientras que en el segundo grupo el 90 por ciento de los usuarios de redes sociales opta por Facebook y sólo el 19 por ciento por Tuenti. (p.1)

Según Arteaga (2012), Tuenti es una red social fundada en España en 2006 que cuenta con más de 14 millones de usuarios y que es responsable del $15 \%$ del tráfico web de ese país(p.1).

En Francia, Delaunay y Metton (2010), en su estudio sobre los jóvenes y los medios de comunicación en ese país, señalan que "[...] los adolescentes son generalmente calificados por los adultos, como 'la generación internet' por haber crecido con las tecnologías de la información y la comunicación (TICS), notablemente con el teléfono celular e internet"(p.1). (Traducción libre). Además, señalan que

[...] en esta cultura común, marcada por la preponderancia de la sociabilidad, los valores de autenticidad, de expresión de sí y de comunicación interpersonal, la transmisión horizontal de valores culturales parece más fuerte y más activa que la transmisión vertical tal y como lo operaba el "programa institucional" a través de la escuela y los padres (p.1).(Traducción libre)

Comunicar e informar al estudiantado: retos de los compromisos de mejoramiento de las carreras universitarias

Alexandra Arrieta Espinoza y Elsiana Guido Guido

DOI: http://dx.doi.org/10.22458/caes.v8i1.1773

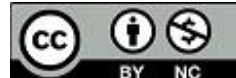

Artículo protegido por licencia Creative Commons 
Estas autoras señalan también "el desarrollo de un proceso de emancipación de los jóvenes en cuanto a las prácticas mediáticas como el uso del teléfono celular, la computadora, conexión personal a internet, televisión y consola de videojuegos"(p.1) Para Livingstone (2004), este proceso de emancipación permite la constitución de "[...] un espacio único en el cual los adolescentes pueden expresar su identidad, ejercer un control personal y dirigir a distancia su relación con la familia y los amigos" (p.1). (Traducción libre)

Coëffé (2015) señala en su estudio realizado también en Francia sobre los jóvenes, Internet y las redes sociales, que

[...] los adolescentes entre 13 a 19 años pasan en promedio 13:30 horas por semana conectados a internet, en ese mismo estudio se señala que la red social Facebook, ocupa el primer lugar ya que el $78 \%$ de los adolescentes están inscritos, seguido por Twitter (25\%) e Instagram (14\%). El $42 \%$ de los jóvenes utiliza la red Facebook, Messenger, 26\% Skype, 23\% Snapchat y 6\% WhatsApp (p.1). (Traducción libre)

Según ese mismo autor (2016), en un estudio sobre las redes sociales más utilizadas en Francia según la edad de los internautas,

[...] la red social Facebook es utilizada por el $62.9 \%$ de los internautas franceses, Google por el $21.6 \%$, Mis viejos amigos $19.6 \%$, Twitter $18,3 \%$ y Linkedin por un 1 $4,6 \%$. Los medios más populares entre los jóvenes de 15 a 24 años son Snapchat, Twitter, Google (p.1). (Traducción libre)

En ese mismo estudio se indica que "el $75 \%$ de los jóvenes de 15 a 24 años, utilizan las redes sociales cada día y que $92 \%$ ingresan al menos una vez por mes"(p.1). (Traducción libre)

Comunicar e informar al estudiantado: retos de los compromisos de mejoramiento de las carreras universitarias

Alexandra Arrieta Espinoza y Elsiana Guido Guido

DOI: http://dx.doi.org/10.22458/caes.v8i1.1773

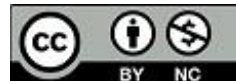

Artículo protegido por licencia Creative Commons 
En América Latina, Barrios (2008) en sus estudios sobre los jóvenes y la red, realizados en la Universidad colombiana, Jorge Tadeo Lozano, afirma que según la población estudiada:

...las tecnologías de la información y comunicación (TICS) son una buena herramienta para el acceso a la información, pues les permite estar enterados del acontecer nacional e internacional y que además les simplifica la labor de búsqueda de datos requeridos para la formación académica (p.272).

En dicho estudio, se explica igualmente que

[...] la red constituye, además, un mecanismo que permite acceder a los datos actualizados de entretenimiento, ocio, etc.; es decir que los jóvenes se actualizan, a través de la red, en tecnología y diversión (juegos); Internet propone guías de comportamiento social para seguir y es un mecanismo que les permite darse a conocer y conocer a los demás (p.272).

Asimismo, González (2010) realiza un estudio sobre los medios de comunicación entre estudiantes de la Universidad Autónoma de México con cuatro objetivos principales, a saber:

definir los medios de comunicación utilizados con mayor frecuencia por alumnos de la carrera de Comunicación y Periodismo de la Facultad de Estudios Superiores de Aragón, para mantenerse informados; saber si utilizan el internet como la fuente de información más recurrente; reconocer cuáles son las temáticas de mayor interés entre los estudiantes en los medios de comunicación; conocer la razón por la cual prefieren ese medio para mantenerse informados. Los resultados más relevantes indicaron que

[...] el medio más utilizado es el internet, seguido por el periódico, la televisión y por la radio. Los hombres en su mayoría mencionaron que tenían preferencia por la forma y el contenido. Al contrario de las mujeres que lo prefieren por la accesibilidad. (Diapositiva 15)

Comunicar e informar al estudiantado: retos de los compromisos de mejoramiento de las carreras universitarias

Alexandra Arrieta Espinoza y Elsiana Guido Guido

DOI: http://dx.doi.org/10.22458/caes.v8i1.1773

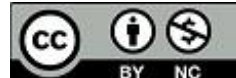

Artículo protegido por licencia Creative Commons 
En Costa Rica, según el estudio del periódico El Financiero (2015), cuyos objetivos eran conocer los medios de comunicación más utilizados por la población costarricense, realizado a una muestra de 600 personas, entre 13 a 65 años, residente en la Gran Área metropolitana, "[...] el celular forma parte del cotidiano y el $71 \%$ declara usarlo todos los días durante todo el día. Es la forma más frecuente para conectarse a Internet". (Diapositiva 5). Este estudio demuestra que las personas jóvenes, entre 12 y 34 años son las que utilizan con mayor frecuencia las redes sociales; dentro de estos, un $78 \%$ de las personas con educación universitaria las utilizan en Costa Rica. (Diapositiva 3)

\subsection{Uso de redes sociales en la academia.}

De acuerdo con un estudio realizado con estudiantes de la Universidad de Málaga, en España, a estudiantes con una edad promedio de 21,62 años, la utilización de redes sociales se ha implantado en el acontecer diario del estudiantado universitario (Gómez, M., Roses, S. y Farias, P., 2012, p. 131), sin embargo, su uso académico no está aún extendido. Los autores consideran como una posible causa de ese uso poco intensivo de las redes sociales para fines académicos, en que tanto el profesorado como las mismas universidades no les otorgan importancia. (p.136).

El limitado uso académico de las redes sociales, señalan Gómez, Roses y Farias, (2012) podría deberse a que "[...] en las universidades podría estar aún muy arraigada la enseñanza tradicional formal, donde la comunicación siempre es unidireccional (profesor-alumno) y donde al alumno le cuesta más participar y sentirse integrado" (p. 136). Los autores proponen que el profesorado, a pesar del desfase generacional que tienen (entre el alumnado que es nativo digital y el personal académico que es en su mayoría pertenece a la

Comunicar e informar al estudiantado: retos de los compromisos de mejoramiento de las carreras universitarias

Alexandra Arrieta Espinoza y Elsiana Guido Guido

DOI: http://dx.doi.org/10.22458/caes.v8i1.1773

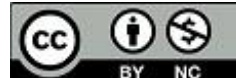

Artículo protegido por licencia Creative Commons 
categoría denominada inmigrantes digitales), incorporen en sus planificaciones docentes el uso activo de las redes sociales que hacen los y las estudiantes (p.136). Este mismo razonamiento puede aplicarse a nivel institucional, es decir, las universidades como organizaciones deben de conocer estas tendencias comunicacionales de las personas jóvenes que atienden y, organizar sus estrategias de comunicación y divulgación tomando en consideración estas características.

Las investigaciones anteriormente citadas evidencian la importancia que está cobrando el tema de la comunicación entre personas jóvenes y el uso del Internet y redes sociales que hace este sector. La población joven muestra características particulares en sus estilos de comunicación, ya que privilegia el uso de las tecnologías de la información para mantenerse informada; sin embargo, en el ámbito de la educación superior, pareciera que su uso para fines de comunicación y divulgación de temas académicos es poco frecuente, tanto por docentes como por estudiantes.

Dado lo anterior, la carrera de Bachillerato en Francés decidió realizar un estudio, más detallado, que le permitiera tener información para la toma de decisiones en lo que respecta a la divulgación de la información académica.

\section{Metodología.}

Como parte del seguimiento a los objetivos del CM, referidos a la mejora de las estrategias de comunicación y divulgación de información entre el estudiantado de la carrera de Bachillerato en Francés y personal docente, la Comisión de autoevaluación y certificación a la calidad de la carrera, con la asesoría del Centro de Evaluación Académica (CEA) y de la

Comunicar e informar al estudiantado: retos de los compromisos de mejoramiento de las carreras universitarias

Alexandra Arrieta Espinoza y Elsiana Guido Guido

DOI: http://dx.doi.org/10.22458/caes.v8i1.1773

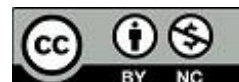

Artículo protegido por licencia Creative Commons 
Oficina de Divulgación (ODI), decidió realizar un diagnóstico para indagar acerca de los medios de comunicación que utiliza, de manera más frecuente, el estudiantado de la carrera. De este modo, se confeccionó, de manera colectiva, una encuesta cuyo objetivo fue conocer e indagar los hábitos de comunicación de esa población.

Para este efecto, de acuerdo con la organización de la Comisión, las personas encargadas del componente currículum, en donde se incluyó el objetivo relacionado con la elaboración de una estrategia de divulgación, elaboraron una encuesta con la asesoría de las instancias universitarias señaladas y con la participación de las demás personas integrantes de la Comisión.

El instrumento diseñado se distribuyó en toda la población estudiantil de la carrera de Bachillerato en Francés, compuesta por 179 estudiantes, de manera que se realizó un censo porque se consultó a toda la población estudiantil.

El instrumento consta de 7 preguntas, en algunas de ellas se debía completar información y en otras seleccionar entre varias opciones. Se les consultó acerca del grado de información que tenían sobre lo que sucedía en la Escuela de Lenguas Modernas y cómo les gustaría ser informados (por correo, vallas, talleres, redes sociales, mensajes de texto). Además, se les preguntó sobre los medios que utilizan para comunicarse con sus compañeros y compañeras, y en su vida personal en general.

Comunicar e informar al estudiantado: retos de los compromisos de mejoramiento de las carreras universitarias

Alexandra Arrieta Espinoza y Elsiana Guido Guido

DOI: http://dx.doi.org/10.22458/caes.v8i1.1773

\section{(c) (i) (5)}


Posteriormente, se contabilizaron las respuestas de cada estudiante y se calculó el porcentaje de respuesta por cada pregunta. Los resultados obtenidos se plantean en el apartado siguiente.

\section{Resultados y su análisis.}

\subsection{Información general de la población consultada}

Los resultados obtenidos evidencian que la mayoría de la población estudiantil consultada son mujeres (77\%), y que únicamente un $23 \%$ de las personas que cursan la carrera son hombres.

En lo que respecta a la edad de la población consultada, se puede constatar que esta se divide en dos grandes grupos semejantes en su porcentaje: un $47 \%$ manifiesta tener 20 años o menos y un $51 \%$ tiene entre 21 y 30 años, lo que evidencia que se trata de personas consideradas como jóvenes, según la clasificación de la UNESCO.

\subsection{Situación académica del estudiantado}

Los resultados muestran que, de los 179 estudiantes consultados, casi la mitad se encontraba en el primer año de la carrera de Bachillerato en Francés, un 30\% cursaba el segundo año; el $14 \%$ el tercero, mientras que un $12 \%$ el último año de la carrera. Un $70 \%$ del estudiantado encuestado cursa solamente la carrera de Bachillerato en Francés, mientras que un $29 \%$ indica haber matriculado otra carrera.

Comunicar e informar al estudiantado: retos de los compromisos de mejoramiento de las carreras universitarias

Alexandra Arrieta Espinoza y Elsiana Guido Guido

DOI: http://dx.doi.org/10.22458/caes.v8i1.1773

\section{(c) (i) (5)}


Las segundas carreras en las que el estudiantado indicaba estar matriculado, además del Bachillerato en Francés, pertenecen a las áreas de: Artes y Letras, Ciencias Agroalimentarias, Ciencias Sociales, Ciencias Básicas, Salud e Ingeniería.

\subsection{Medios de comunicación utilizados por el estudiantado}

En el estudio realizado se indagó acerca de los medios de comunicación utilizados por el estudiantado para informarse sobre tres aspectos de interés: 1. lo que acontece en la Escuela de Lenguas Modernas, 2. para comunicarse con sus pares y en su vida personal y, para informarse sobre temas académicos y laborales de su interés.

En lo que respecta a los medios de comunicación utilizados por el estudiantado para informarse sobre lo que acontece en la Escuela de Lenguas Modernas se encontró que se trata de una población joven estudiantil, desinformada sobre lo que acontece en su medio académico cercano, específicamente en la Escuela en la que está empadronada puesto que un $87 \%$ de las personas consultadas indicaron estar desinformadas y no estar al tanto de lo que acontece en la Escuela de Lenguas Modernas. Solamente un $13 \%$ indicó que sí está al tanto del acontecer de su Escuela.

Por otra parte, el estudiantado manifiesta que se entera de las actividades relacionadas con la carrera, sobre todo "de boca en boca", es decir, lo que se le transmite de manera oral, ya sea por sus compañeros y compañeras o docentes.

Comunicar e informar al estudiantado: retos de los compromisos de mejoramiento de las carreras universitarias

Alexandra Arrieta Espinoza y Elsiana Guido Guido

DOI: http://dx.doi.org/10.22458/caes.v8i1.1773

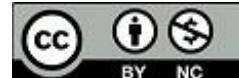


Otro dato importante, obtenido del sondeo realizado es que la red social Facebook es la más utilizada por la población estudiantil consultada. Otros medios son también utilizados para informarse, tales como las pizarras informativas, que son pizarras físicas administradas por las Escuelas o Facultades, en donde se coloca información actualizada sobre diversos aspectos del quehacer académico y cultural, el correo electrónico y la página web de la Universidad de Costa Rica, tal y como se aprecia en el gráfico No 01.

\section{Gráfico No. 01}

Bachillerato en Francés: Medios utilizados por la población estudiantil del Bachillerato en Francés para informarse sobre actividades académicas 0 de otra índole (en números absolutos)

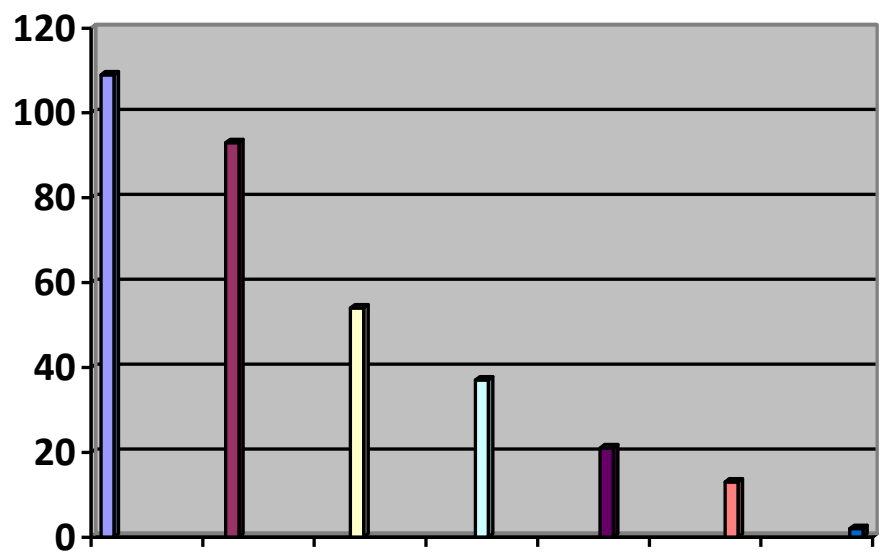

$\square$ De boca en boca
$\square$ Facebook UCR
$\square$ Pizarras
$\square$ Correo electrónico
$\square$ Página web UCR
$\square$ Boletines informativos
$\square$ Otros medios

Número de

estudiantes

Fuente: Elaboración propia.

Comunicar e informar al estudiantado: retos de los compromisos de mejoramiento de las carreras universitarias

Alexandra Arrieta Espinoza y Elsiana Guido Guido

DOI: http://dx.doi.org/10.22458/caes.v8i1.1773

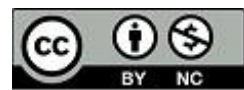


En lo que respecta a los medios de comunicación utilizados con mayor frecuencia por el estudiantado para comunicarse con sus pares y en su vida personal, los resultados obtenidos parecen indicar, que para la población estudiantil no hay mayor diferencia en el uso de los medios de comunicación utilizados con sus pares o en su vida personal. De este modo, 169 de las 179 personas encuestadas manifestaron utilizar mayormente el WhatsApp como medio de comunicación con sus pares y en su vida personal. En menor medida se utiliza el Facebook, el correo electrónico y las llamadas telefónicas.

Los resultados del estudio parecen indicar que el WhatsApp es el medio que se usa de forma más frecuente, seguido por el Facebook y en menor medida por otras formas de comunicación como el correo electrónico, llamadas telefónicas, otras redes y mensajes de texto, como se señala en el gráfico No 02.

Comunicar e informar al estudiantado: retos de los compromisos de mejoramiento de las carreras universitarias

Alexandra Arrieta Espinoza y Elsiana Guido Guido

DOI: http://dx.doi.org/10.22458/caes.v8i1.1773

\section{(c) (i) (5)}


Gráfico No. 02

Bachillerato en Francés: Medios utilizados por la población estudiantil del Bachillerato en Francés para comunicarse con sus pares y en su vida personal

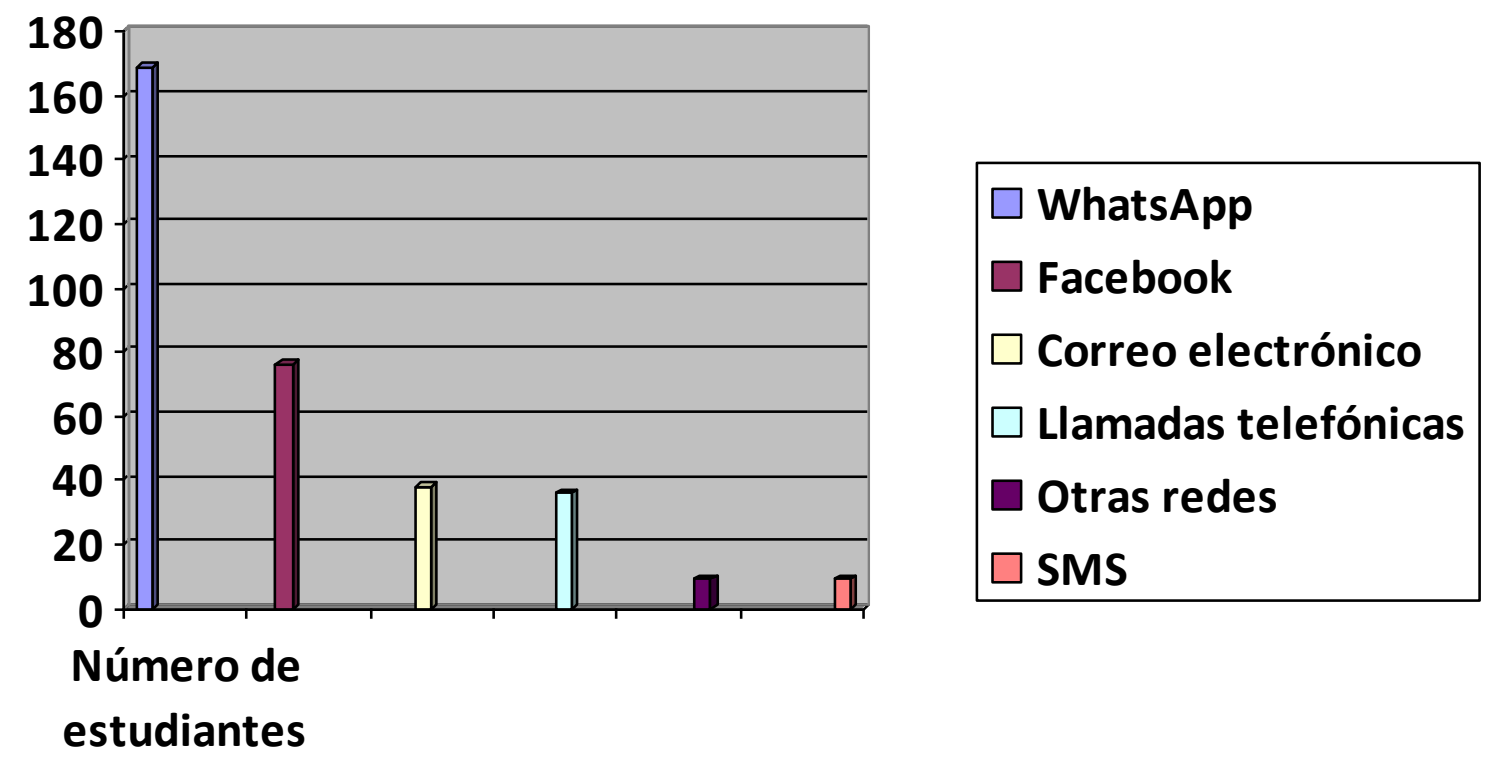

Fuente: Elaboración propia

Al estudiantado se le consultó, además, acerca de los medios por los cuales le gustaría ser informado de las actividades y proyectos que realiza la Escuela, y los resultados señalan que una gran mayoría (127 de las 179 personas encuestadas), prefiere que se utilice el correo electrónico, seguido por una cantidad importante (102 de las 179 personas encuestadas) que preferiría que se utilice la red social Facebook.

También se señala a las pizarras informativas, el WhatsApp y los mensajes de texto como medios que se utilizarían para informarse.

Comunicar e informar al estudiantado: retos de los compromisos de mejoramiento de las carreras universitarias

Alexandra Arrieta Espinoza y Elsiana Guido Guido

DOI: http://dx.doi.org/10.22458/caes.v8i1.1773

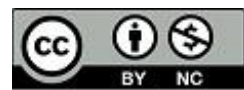


En menor medida se mencionan el Instagram y las llamadas telefónicas, tal y como se muestra en el gráfico No. 03. Cabe indicar que las personas podían escoger más de un medio.

Gráfico No. 03

Bachillerato en Francés: Medios de comunicación por los cuales desearía ser informada la población estudiantil del Bachillerato en Francés (en números absolutos)

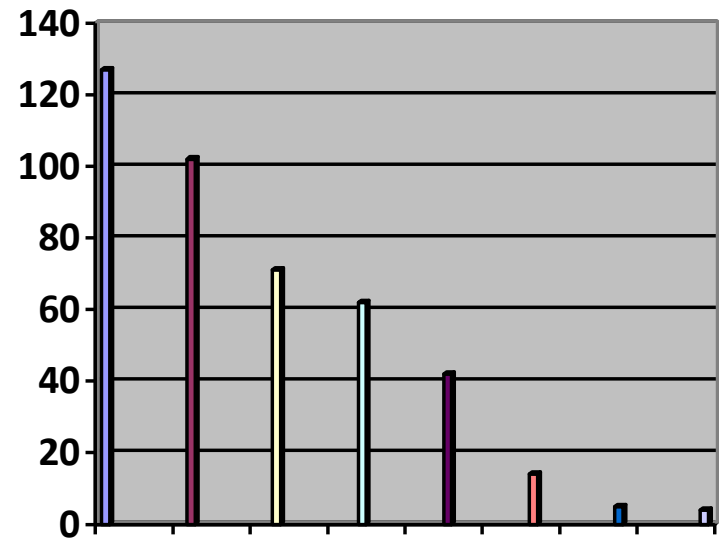

Número de estudiantes

$\square$ Correo electrónico
$\square$ Facebook
$\square$ Pizarras
$\square$ WhatsApp
$\square$ SMS
$\square$ Instagram
$\square$ Llamadas telefónicas
$\square$ Otros

Fuente: Elaboración propia.

Finalmente, en lo que respecta a temas académicos y laborales de interés para la población estudiantil, al estudiantado se le consultó acerca de los temas relacionados con la carrera sobre los cuales desearía ser informado. Las respuestas se pueden clasificar en dos grupos:

Comunicar e informar al estudiantado: retos de los compromisos de mejoramiento de las carreras universitarias

Alexandra Arrieta Espinoza y Elsiana Guido Guido

DOI: http://dx.doi.org/10.22458/caes.v8i1.1773

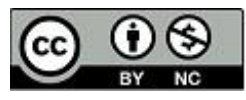

Artículo protegido por licencia Creative Commons 
las que tienen relación con aspectos académicos y las que se relacionan con aspectos laborales. En ese sentido, se señala que la mayoría de la población consultada indica estar interesada en recibir información en actividades académicas en general, sobre el proceso de matrícula (169 de las 179 personas encuestadas) e información sobre becas (134 de las 179 personas encuestadas).

En cuanto al aspecto laboral, se desea recibir información sobre las ofertas laborales (146 de las 179 personas encuestadas) y ferias de empleo que permitan conocer las demandas del mercado laboral o, eventualmente, incorporarse al mismo (136 de las 179 personas encuestadas). Cabe señalar, que las personas podían escoger más de un tema.

\section{Conclusiones}

Como se explicó, la gestión de la calidad implica desarrollar procesos investigativos que generen información que sustente la toma de decisiones; de este modo, elaborar una estrategia de comunicación y divulgación de una carrera, en el marco de procesos de mejoramiento continuo, implicó el planeamiento y desarrollo de un sondeo que permitiera conocer aspectos fundamentales en cuanto a los gustos y preferencias del estudiantado de la carrera de Bachillerato en Francés.

Las comunicaciones en las unidades académicas, dirigidas al estudiantado, deben de considerar varios aspectos, entre los cuales se mencionan: las características de esa población, sus gustos e intereses para lograr emitir un mensaje pertinente y efectivo. Se parte de la consideración de que los objetivos de mejora de las carreras, relacionados con temas de divulgación e información deben desarrollarse tomando en consideración la mayor

Comunicar e informar al estudiantado: retos de los compromisos de mejoramiento de las carreras universitarias

Alexandra Arrieta Espinoza y Elsiana Guido Guido

DOI: http://dx.doi.org/10.22458/caes.v8i1.1773

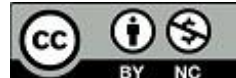

Artículo protegido por licencia Creative Commons 
cantidad de información posible, para lo cual los estudios brindan información relevante para la toma de decisiones.

En el caso de la carrera de Bachillerato en Francés, uno de los objetivos resultantes del proceso de certificación al que se sometió, buscaba la forma más eficiente de informar y divulgar, y para contar con información oportuna para la toma de decisiones, se elaboró un estudio que permitiera conocer de forma más precisa las características del estudiantado y cómo se informan y les gustaría ser informados con el objetivo de optimizar la divulgación de la información que la unidad académica quiere transmitir a su estudiantado.

Para determinar si los medios de comunicación eran pertinentes, se le preguntó al estudiantado cómo se informaban de las diferentes actividades e informaciones divulgadas por la UCR y por la propia Escuela de Lenguas Modernas.

La principal conclusión de esta investigación apunta a que la unidad académica no utiliza el mismo canal de comunicación que usa el estudiantado. Así, los mensajes no están teniendo el efecto deseado y no se logra mantener a una población estudiantil informada de aquellos aspectos de interés especial para la carrera y para la vida estudiantil de esta población.

Se podría pensar que la mejor estrategia de comunicación para la unidad académica, supone la utilización de los medios de comunicación que utiliza el público estudiantil, es decir: las redes sociales y en particular WhatsApp. Esta tendencia implica un acercamiento diferente a la manera en que tradicionalmente se maneja la comunicación en las unidades académicas, por cuanto se trata de una comunicación más horizontal, utilizando para ello medios en los

Comunicar e informar al estudiantado: retos de los compromisos de mejoramiento de las carreras universitarias

Alexandra Arrieta Espinoza y Elsiana Guido Guido

DOI: http://dx.doi.org/10.22458/caes.v8i1.1773

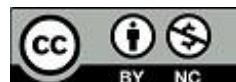

Artículo protegido por licencia Creative Commons 
que el estudiantado se informa, pero también colabora. Con esta propuesta, el énfasis de la carrera estaría puesto en perfilarse como "moderador" de la comunicación. Esta comunicación más horizontal permite, entonces, mayor participación al estudiantado e implica el uso de las redes sociales.

Sin embargo, se conoce el poco uso académico de las redes sociales, sobre todo en aspectos de la gestión de la calidad de las carreras, Gómez, Roses y Farias, (2012) señalan que esto podría deberse a que "[...] en las universidades podría estar aún muy arraigada la enseñanza tradicional formal, donde la comunicación siempre es unidireccional (profesoralumno) y donde al alumno le cuesta más participar y sentirse integrado" (p. 136).

A esto se refiere también Dubet (2006), quien reflexiona sobre la posibilidad de nuevas formas institucionales, este autor sugiere

[...] pasar del modelo construido a partir del modelo de la Iglesia- la primera de las instituciones en encargarse por vocación, del prójimo - a un modelo basado en la profesionalización de los actores y sobre todo teniendo en cuenta el creciente aumento de las capacidades de estos (p.1). (Traducción libre)

El uso de las redes sociales para divulgar, informar y sobre todo para interactuar en un modelo de comunicación en red, pareciera ser lo que le interesa al estudiantado universitario consultado. Tal y como lo señala Guillermo López de la Universidad de Valencia, en un estudio realizado sobre el efecto de las tecnologías de la información y comunicación en la conformación de la opinión pública (2006), se ha pasado de un modelo, que él denomina tradicional de comunicación de masas a un modelo de comunicación en red (p. 233). El

Comunicar e informar al estudiantado: retos de los compromisos de mejoramiento de las carreras universitarias

Alexandra Arrieta Espinoza y Elsiana Guido Guido

DOI: http://dx.doi.org/10.22458/caes.v8i1.1773

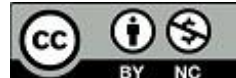


primero se caracteriza, sobre todo, por ser fuertemente jerarquizado y unidireccional, mientras que el modelo de comunicación en red se caracteriza por ser multidireccional y horizontal (p. 233).

Este cambio de paradigma lo atribuye López (2006), como "[...] consecuencia del desarrollo de las distintas aplicaciones de la tecnología digital, y muy particularmente Internet" (p. 237), ya que dicha red ofrece "[...] un sistema de transmisión eminentemente descentralizado y abierto, un orden en el caos, difícilmente controlable por instancia alguna, sea pública o privada" (p. 237).

Este nuevo paradigma, explicado por López (2006), implica importantes reconsideraciones para las carreras en lo que se refiere a su relación con el estudiantado y el material que se les debe entregar, compartir o informar como producto de sus procesos de mejora continua y acreditaciones. Lo anterior, implica considerar al estudiantado de la carrera como un público no abocado únicamente a recibir de manera pasiva la información por parte de las carreras, puesto que ahora esta población puede, como lo menciona López (2006) “[...] modificarla o interpretarla individualmente o en colaboración con otros usuarios de redes de comunicación, generar informaciones $u$ opiniones propias e incluso constituirse en fuente para los propios medios de comunicación social” (p.239).

En este sentido, el ecosistema mediático, como denomina López (2006) a la nueva reconfiguración de la comunicación, implica una convivencia de dos sistemas: el modelo tradicional que convive con "[...] un público activo, policonsumidor de medios y que crea incesantemente nuevos espacios de generación de informaciones y opiniones [...]" (p. 239).

Comunicar e informar al estudiantado: retos de los compromisos de mejoramiento de las carreras universitarias

Alexandra Arrieta Espinoza y Elsiana Guido Guido

DOI: http://dx.doi.org/10.22458/caes.v8i1.1773

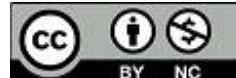


Eucario Parra (2010) encontró en su estudio que a los jóvenes universitarios no les resultan ajenas las redes sociales, pues ellos, menciona el autor,

[...] aun con sus intereses académicos van a estas comunidades no exactamente a eventos de ese tipo. Ellos van a estas redes a satisfacer necesidades de pertenencia, diversión o simplemente, por curiosidad. Lo cierto es que este entorno no es ajeno a ellos" (p.116).

Según Parra (2010), entonces, los jóvenes universitarios usan las redes sociales no solo con aspiraciones académicas, cognitivas o de aprendizaje. Pero insiste que, desde la perspectiva de las personas jóvenes, de los nativos digitales, puede decirse que tiene usos necesarios, pues tal y como lo explica "

[...] pueden existir motivaciones no académicas que lleven a los jóvenes a Facebook. Es decir, existen otras necesidades, por ejemplo, ser entendidos, ser escuchados, ser participativos. En estos términos, en las comunidades sociales de Internet, los jóvenes encuentran satisfactores que los conducen a la producción de ideas, al sostenimiento de diálogos de todo tipo, al encuentro de mensajes que coinciden con sus intereses" (p. 115).

Parra (2010) menciona que

[...] las redes son escenarios para la interacción social, definidas desde un intercambio dinámico entre personas en la web. Se caracterizan por ser grupos de personas que se identifican por las mismas necesidades y problemáticas. Es tan avasallante su impacto, que para los nativos digitales (personas menores de 25 años) su pertenencia a estas redes puede considerarse un asunto ya natural (p. 112).

Sixou (2011) sugiere al respecto que:

[...] las redes sociales son espacios colaborativos y conversacionales, plataformas de expresión que permiten el intercambio de datos entre los miembros de la comunidad de una red. Los miembros deben participar, contribuir con la elaboración

Comunicar e informar al estudiantado: retos de los compromisos de mejoramiento de las carreras universitarias

Alexandra Arrieta Espinoza y Elsiana Guido Guido

DOI: http://dx.doi.org/10.22458/caes.v8i1.1773

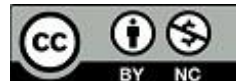

Artículo protegido por licencia Creative Commons 
de las temáticas. Compartir datos en forma de textos, videos, fotografías, enlaces etc., permite la interacción entre individuos cuyos centros de interés son los mismos. (Traducción libre) (Diapositiva 8).

Tomando en cuenta la afirmación anterior, la integración de las redes sociales en las estrategias de comunicación de las unidades académicas de los centros de enseñanza superior permitiría, eventualmente, la adaptación de los canales tradicionales de comunicación, orientados de manera vertical y unidireccional a canales horizontales y multidireccionales, donde convergen diferentes saberes y actores: estudiantes, docentes, administrativos, egresados, empleadores, colaboradores externos entre otros.

La participación de los diferentes miembros de una comunidad por medio de sus aportes, recomendaciones, discusiones, etc., enriquecería las estrategias de comunicación. Es decir, que las instituciones de educación superior deberían tener en cuenta los crecientes cambios de la sociedad actual, específicamente en cuanto a los medios de comunicación y divulgación de la información, con el fin de permitir a todos los individuos que conforman el medio académico de proceder con mayor autonomía y responsabilidad. Cabe plantearse aquí, si la UCR u otras instituciones de Educación Superior están preparadas para una apertura hacia estrategias de la divulgación y comunicación multidireccionales que incluyan la participación de todos los miembros de una comunidad académica.

Finalmente, vale señalar que durante el VII Congreso Universitario desarrollado en la UCR en el año 2014, la Oficina de Divulgación (ODI) presentó una ponencia en la que proponía el cambio de nombre de esta oficina al de Oficina de Comunicación Institucional; esta propuesta se fundamentó en que el accionar de la ODI, consideran las autoras de la

Comunicar e informar al estudiantado: retos de los compromisos de mejoramiento de las carreras universitarias

Alexandra Arrieta Espinoza y Elsiana Guido Guido

DOI: http://dx.doi.org/10.22458/caes.v8i1.1773

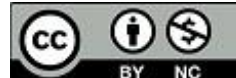

Artículo protegido por licencia Creative Commons 
ponencia, se ha centrado en el Reglamento, en la divulgación del quehacer universitario, de donde deriva una ausencia de políticas institucionales de comunicación (Luz Marina Rivera, María Peña Bonilla, María del Mar Izaguirre, Rebeca Chaves González y Guadalupe Rojas Víquez, 2014, p.2).

El análisis realizado acerca de la situación de la ODI señala que la divulgación

[...] no es ya el eje central de la comunicación de una institución con un gran impacto social en diferentes ámbitos de la comunidad costarricense, sino que ahora resulta de suma relevancia la articulación de las acciones y espacios comunicacionales entre la Universidad y sus diferentes públicos. (p. 5).

Se espera en un próximo estudio, analizar la estrategia de comunicación y divulgación propuesta por la carrera de Bachillerato en Francés de la UCR, en cuanto a la participación, colaboración, sugerencias, interacción, e intercambio de información de los miembros implicados.

Comunicar e informar al estudiantado: retos de los compromisos de mejoramiento de las carreras universitarias

Alexandra Arrieta Espinoza y Elsiana Guido Guido

DOI: http://dx.doi.org/10.22458/caes.v8i1.1773

\section{(c) (i) (5)}




\section{Referencias}

Alarcón, F. (2016). Autoevaluación y gestión de la calidad en la educación superior centroamericana. (Diapositivas en Power Point). Consejo Superior Universitario Centroamericano. CSUCA.

Arteaga, S. (2012). ¿Qué es y cómo usar Tuenti, la red social española? Computer hoy. com. España. Recuperado de http://computerhoy.com/noticias/internet/que-es-comousar-tuenti-red-social-espanola-2436/ Consultado el 20 de junio de 2016.

Barrios, A. (2009). Los jóvenes y la red: usos y consumos de los nuevos medios en la sociedad de la información y la comunicación. Revista Signo y Pensamiento, 28 (54).

Centro Interuniversitario de Desarrollo (CINDA). (2012). Aseguramiento de la calidad en Iberoamérica. Educación Superior. Informe 2012. Chile. RIL editores.

Coëffé, T. (2015). Les réseaux sociaux les plus utilisés en France selon l'âge des internautes. Blog du Modérateur. Recuperado de http://www.blogdumoderateur.com/reseauxsociaux-france-2015/ Consultado el 10 de setiembre de 2016.

Coëffé, T. (2016). Étude IPSOS: les jeunes, Internet et les réseaux sociaux .Blog du Modérateur. Recuperado de: http://www.blogdumoderateur.com/etude-ipsos-juniorconnect-2015/ Consultado el 10 de setiembre de 2016.

Delaunay, H. y Metton, C. (2010). Les adolescents et leurs pratiques de communication :nouveaux objets, nouveaux usages. En Centre national de la fonction publique territoriale. Les nouvelles pratiques culturelles des jeunes et les bibliothèques à l'ère du numérique (pp. 1-6), Angers: CNFPT Pays de la Loire. Recuperado de http://www.bibliotheques93.fr/fichiers/pratiques culturelles adolescents/HDelaunayCMetton intervention24-11.pdf/ Consultado el 8 de octubre de 2016.

Dubet F. Le Déclin de l'institution, Paris, Seuil, (2002). FLUCKIGER C., « Instrumenter la sociabilité juvénile: l'appropriation des blogs dans un groupe de collégiens ", Réseaux, 138, 2006. Recuperado de

Comunicar e informar al estudiantado: retos de los compromisos de mejoramiento de las carreras universitarias

Alexandra Arrieta Espinoza y Elsiana Guido Guido

DOI: http://dx.doi.org/10.22458/caes.v8i1.1773

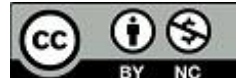

Artículo protegido por licencia Creative Commons 
http://www.bibliotheques93.fr/fichiers/pratiques culturelles adolescents/HDelaunayCMetton intervention24-11.pdf/ Consultado el 8 de octubre de 2016.

Estudio que detalla el uso que hacen los costarricenses de Internet y redes sociales.

(28 de junio del 2015). El Financiero. Recuperado de www.elfinancierocr.com/gnfactory/especiales/2015/red506/ResumenRED506.pdf/ Consultado el 5 de mayo de 2016.

Livingstone, S. (2016) Reframing media effects in terms of children's rights in the digital age.Journal of Children and Media, 10 (1). pp. 4-12. ISSN 1748-2798. Recuperado de http://www.tandfonline.com/doi/full/10.1080/17482798.2015.1123164/Consultado el 9 de noviembre de 2016.

Irekia. (2012) Televisión e internet, medios preferidos para informarse, formarse y entretenerse en Euskadi. Euskadi. Eus. Recuperado en http://www.euskadi.eus/ Consultado el 5 de octubre de 2016.

Irekia. (2012) El uso de Internet establece una frontera clara entre las generaciones jóvenes y las adultas. Euskadi. Eus. Recuperado en http://www.euskadi.eus/ Consultado el 5 de octubre de 2016.

Gómez, M., Roses, S. y Farias, P. (2012). El uso académico de las redes sociales en universitarios. Comunicar. Revista Científica de Educomunicación, 38, (XIX), 131-138.

González, A. (2010). Comunicación y periodismo: estadística aplicada a la comunicación. (Diapositivas en PowerPoint).

Guido, E., Calderón, L. y Gallardo, E. (2011) Aspectos priorizados en los planes de mejora de las carreras acreditadas y fomento de una cultura de evaluación en la Universidad de Costa Rica. Revista Actualidades Investigativas en Educación,11(2) pp. 1-24

Jaramillo, A. y Montoya, Á. (2007). Mejoramiento continuo en la educación superior. La experiencia reciente en la Universidad EAFIT. Revista Universidad EAFIT., 43(146), 20-32.

Livingstone S., « Du rapport entre audiences et publics », Réseaux. 126(22), 17-55.

Comunicar e informar al estudiantado: retos de los compromisos de mejoramiento de las carreras universitarias

Alexandra Arrieta Espinoza y Elsiana Guido Guido

DOI: http://dx.doi.org/10.22458/caes.v8i1.1773

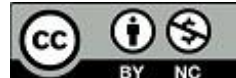

Artículo protegido por licencia Creative Commons 
López, G. (2006). Comunicación en red y mutaciones de la esfera pública. Revista de Estudios de Comunicación. ZER. 20, 231-249.

Naval, C. y Sábada, C. (2005). Juventud y medios de comunicación: frente a frente. Revista Juventud. 68, 9-17.

Urrutia, Víctor . (2012). El 96\% de los jóvenes usa internet, la mayoría a diario, y el 83\% utiliza redes sociales. 20 minutos. Recuperado de http://www.20minutos.es/noticia/1350975/0/\#xtor=AD-15\&xts=467263// Consultado el 10 de octubre de 2016.

Vera, J. (2012). Retratos de juventud 15: Medios de comunicación. Bilbao: Gabinete de Prospección Sociológica-Presidencia del Gobierno Vasco.

Real Academia Española. (2001). Certificación. En Diccionario de la lengua española (22.a 2016. ed.). Recuperado de http://dle.rae.es/?id=80VdkYW/ Consultado el 16 de agosto de

Parra, E. (2010). Las redes sociales de internet: también dentro de los hábitos de los estudiantes universitarios. Anagramas, 9(17), 107-116.

Sixou ,D. (2011). Intégrer les réseaux sociaux dans sa stratégie de communication. Comunited. Agence de Communication. Recuperado de http://es.slideshare.net/denissixou/intgrer-les-rseaux-sociaux-dans-sa-stratgie-decommunication-10594048/ Consultado el 10 de setiembre de 2016.

Toro, J. R. (2012). Gestión interna de calidad. Centro Interuniversitario de Desarrollo. Aseguramiento de la calidad en Iberoamérica. Educación Superior. Informe 2012. Chile pp. 190-199.

Universidad de Costa Rica. Facultad de Letras. (2012) Informe final de Autoevaluación carrera de Bachillerato en Francés. Universidad de Costa Rica. Facultad de Letras. (2014) Compromiso de Mejoramiento Bachillerato en Francés 2014-2017.

Comunicar e informar al estudiantado: retos de los compromisos de mejoramiento de las carreras universitarias

Alexandra Arrieta Espinoza y Elsiana Guido Guido

DOI: http://dx.doi.org/10.22458/caes.v8i1.1773

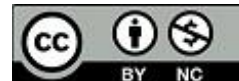

Artículo protegido por licencia Creative Commons 
Rivera Monge, Luz María, Peña Bonilla, María., Izaguirre, María del Mar., Chaves González, Rebeca y Rojas Víquez, Guadalupe. (2014). Modificación del Capítulo VII de Reglamento de la Vicerrectoría de Acción Social. Universidad de Costa Rica.VII Congreso Universitario. Recuperado el 07 octubre, 2016 de http://setimocongreso.ucr.ac.cr/node/265/. Consultado el 07 de setiembre de 2016.

Universidad de Costa Rica. Vicerrectoría de Docencia (2008). Corrección a la Resolución $V D-R-7042-2001$.

Universidad de Costa Rica. Vicerrectoría de vida estudiantil (2001). Normativas de Régimen académico estudiantil. Recuperado de http://www.cu.ucr.ac.cr/normativ/regimen academico estudiantil.pdf/ Consultado el 10 de agosto de 2016.

Universidad de Costa Rica. Vicerrectoría de Docencia. (2015). Resolución VD-R-92272015.

UNESCO (2016). Sobre el Programa de la Juventud. Recuperado de http://www.unesco.org/ Consultado el 20 de setiembre de 2016.

Universidad de Costa Rica. Vicerrectoría de Docencia. (2016). Certificación de la calidad académica: carreras de grado.

Zapata, G. \& Tejeda, I. (2009). Impactos del aseguramiento de la calidad y la acreditación de la educación superior. Consideraciones y proposiciones. Calidad en la Educación 31, 191-209. Recuperado de:

https://www.researchgate.net/profile/Gonzalo Zapata2/publication/44137921 Impactos del aseguramiento de la calidad y acreditacion de la educacion superior Consideraciones y proposiciones/links/556db3a108aeab777224f886.pdf Consultado el 20 de setiembre de 2016.

Comunicar e informar al estudiantado: retos de los compromisos de mejoramiento de las carreras universitarias

Alexandra Arrieta Espinoza y Elsiana Guido Guido

DOI: http://dx.doi.org/10.22458/caes.v8i1.1773

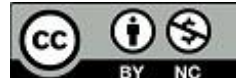

